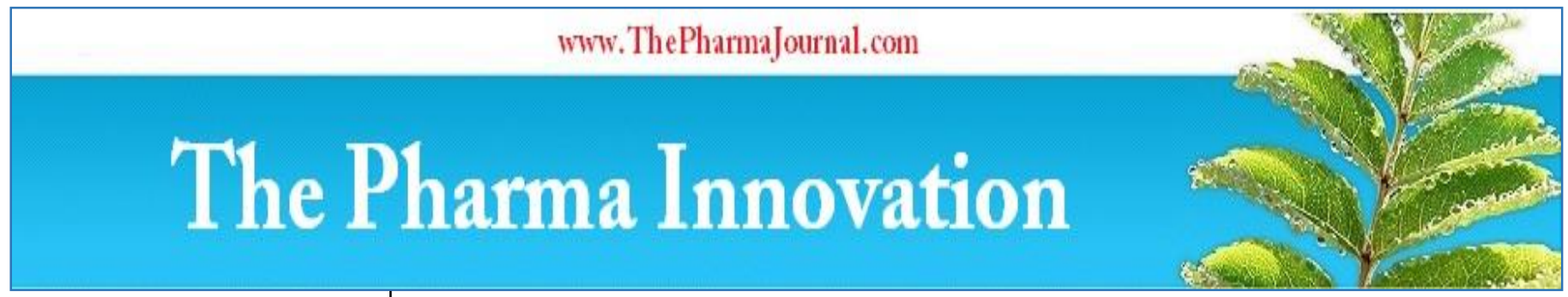

ISSN (E): 2277 - 7695

ISSN (P): 2349-8242

NAAS Rating: $\mathbf{5 . 0 3}$

TPI 2021; 10(2): 414-418

(C) $2021 \mathrm{TPI}$

www.thepharmajournal.com

Received: 18-12-2020

Accepted: 23-01-2021

Ananya Payal

M. Tech, Department of Food

Process Engineering, Indian

Institute of Food Processing

Technology, Thanjavur, Tamil

Nadu, India

\section{Arunkumar Elumalai}

Assistant Professor, Department of Computational Modeling and

Nanoscale Processing Unit,

Indian Institute of Food

Processing Technology,

Thanjavur, Tamil Nadu, India

\section{JA Moses}

Assistant Professor, Department of Computational Modeling and Nanoscale Processing Unit,

Indian Institute of Food

Processing Technology,

Thanjavur, Tamil Nadu, India

\section{Dr. C Anandharamakrishnan}

Director, Indian Institute of

Food Processing Technology,

Thanjavur, Tamil Nadu, India

\section{Corresponding Author:}

Dr. C Anandharamakrishnan

Director, Indian Institute of

Food Processing Technology,

Thanjavur, Tamil Nadu, India

\section{Age as a dominant factor affecting gastric motility and emptying}

\author{
Ananya Payal, Arunkumar Elumalai, JA Moses and Anandharamakrishnan C
}

DOI: https://doi.org/10.22271/tpi.2021.v10.i2f.5701

\begin{abstract}
Gastric motility is the process of continuous propagation of peristaltic waves from the anterior part of the stomach to the pylorus region. These waves aid in the digestion of foods, importantly play a major role in gastric emptying of foods. The present study aimed to investigate whether ageing influences gastric motility in response to apple consumption. Subjects were asked to consume apple and water in the ratio of 3:1 followed by MRI scanning in the right lying position. Antral contraction wave characteristics like speed, frequency, amplitude and width of the wave and occlusion percentage were calculated. Average contractions per minute were obtained as $2.67 \pm 0.06$ for young age and $2.43 \pm 0.22$ for middle-aged healthy humans. From the obtained results, no significant difference was found between the assessed motility parameters.
\end{abstract}

Keywords: Gastric motility, Magnetic resonance imaging, Propagation speed, Antral contraction waves, Stomach

\section{Introduction}

Digestion of foods is a complex process involving both the chemical and mechanical breakdown of foods (Lamond et al., 2019) ${ }^{[18]}$. Digestion primarily starts in the mouth, salivary amylase acts on the food and converts it into a bolus. The bolus is a semi-solid food ball with particles of average particle size less than or equal to $6 \mathrm{~mm}$ (Bornhorst \& Paul Singh, 2014) ${ }^{[4]}$. Movement of the bolus from the mouth to stomach is facilitated by peristalsis. Peristaltic waves travel right from the oesophagus to pyloric region of the stomach carrying out various vital functions in the stomach. In the stomach region, peristaltic waves originate as small indentations from the anterior part, i.e., fundus and deepen when they reach pylorus (Liu et al., 2020) ${ }^{[19]}$. These waves when reach the posterior part of the stomach lead to occlusion of the stomach wall. This process helps in mechanical digestion of foods, as the pressure exerted by the stomach wall squeezes and breaks down the food by processes called fragmentation and erosion (Fanbin Kong \& Singh, 2009) ${ }^{[16]}$. Gastric acid and enzyme-like pepsin carry out the chemical digestion. After completion of digestion, particles less than $2 \mathrm{~mm}$ pass into the duodenum through pylorus valve for further intestinal digestion and nutrient absorption. The process of emptying chyme from the stomach is called as gastric emptying (Gopirajah \& Anandharamakrishnan, 2014) ${ }^{[9]}$. Peristalsis, otherwise called as gastric motility plays a vital role in gastric emptying of foods.

Peristalsis is defined as the propagation of a series of antral contraction waves that originate as shallow indentations from the anterior part of the stomach and deepens while nearing the pylorus at an average of 3 per minute (Schulze, 2006) ${ }^{[30]}$. Gastric motility occurs in four stages during the fasted state. Phase I lasts for 40 to 60 minutes with moderate contraction strength, then phase II occurs with the similar time, but high contraction frequency, followed by a short phase III for 4 to 5 minutes, during which all the undigested material escapes out of the stomach. Phase IV is a transitional phase between phase III and phase I that occurs for 1530 minutes duration. (F. Kong \& Singh, 2008) ${ }^{[15]}$. When a meal is ingested, tonic contractions begin at the proximal part of the stomach that help in the food movement, which when proceed towards the antral region is termed as peristaltic contractions, occur at the rate of 3 cycles per minute (Pal, Brasseur, \& Abrahamsson, 2007) ${ }^{[25]}$. The energy required for the breakdown of food particles is mainly derived from antral contractions (Marciani et al., 2001) ${ }^{[23]}$. These waves contribute to the squeezing effect of food in the antral region, resulting in emptying. Various studies reported that gastric motor function has a significant effect on liquid emptying 
compared to solid emptying, as these waves are responsible for antro-duodenal pressure differences and transpyloric flow (Hausken, Mundt, \& Samsom, 2002) ${ }^{[12]}$. Determination of ACW characteristics and its dependence on age is also a huge scope of the study as it is a primary determinant in assessing gastric emptying behaviour.

Various studies in the literature report the dependence of gastric motor function on physiological factors like age, gender and health status (Camps, De Graaf, \& Smeets, 2018; Hellström, Samuelsson, Al-Ani, \& Hedström, 2017) [13]. Different conclusions were derived on the effect of ageing on gastric motor function. Bonner and team performed a study on gastrointestinal transit time and reported insignificant differences while Madsen and Graff reported the other way, based on various other factors considered (Bonner et al., 2015 ${ }^{[3]}$; Graff, Brinch, \& Madsen, 2001) [11]. Type of meal, the physical state of the meal, calorific value, composition, etc is some other factors that play a key role in regulating gastric motor function (Maes, Ghoos, Geypens, Hiele, \& Rutgeerts,

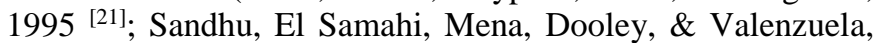
1987) [29]. ACWs of the stomach in vivo is generally determined by various oral administration techniques and image-based techniques. Oral administration techniques include breath test, impedance, smart pill test, etc. while image-based techniques include scintigraphy, ultrasonography, MRI, etc. (Brogna et al., 1998; Camps et al.,

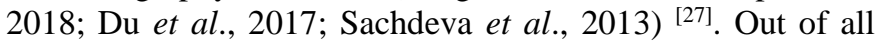
the above-mentioned techniques, MRI is considered more appropriate due to its high resolution and accuracy. This noninvasive technique is more appealing as it can be used to measure gastric emptying and wall motion without exposing the subject to radiation (Parkman, 2018) ${ }^{[26]}$

Among various factors mentioned, gastric motility is one such factor that regulates the process of digestion. A hence deeper understanding of gastric motility parameters provides insights on gastric responses that vary with age and type of food. These help in the formulation of foods based on the response of the gastro-intestinal system. Therefore, the present study is planned to investigate whether age influences gastric motility in humans, which is also a key determinant in the case of gastric emptying. To examine that in vivo trials were performed in two different age groups, young (20-30 years) and middle (40-50 years) and ACW characteristics were analyzed.

\section{Materials and Methods}

\subsection{Selection of subjects and screening}

A total of six healthy volunteers, three from each young and middle age group were selected as subjects. Volunteers with any sort of surgeries, implants or gastrointestinal disorders, pregnant woman, smokers, alcohol addicts are excluded from the study. Subjects were asked to fast overnight (at least $8 \mathrm{hrs}$ ) before scanning. MRI scanning was performed in the early hours from 7.30 am to $10 \mathrm{am}$. All the subjects were given a questionnaire to clarify their health status. A research information sheet was provided before the study procedure in both native (Tamil) and the English language for the information of the volunteers. Finally, written consent was taken from the volunteers about their willingness to participate in the study. The study protocol was approved by the ethical committee of K. A. P. V Govt Medical College and Mahatma Gandhi Memorial Govt Hospital, Tiruchirapalli, Tamil Nadu.

\subsection{Test sample}

Apple, a low GI and high dietary fibre contained fruit commonly preferred by all age groups were selected as the test sample. Fresh and optimum matured red delicious variety apples were selected and procured from local markets of Thanjavur. $300 \mathrm{~g}$ of apple along with $100 \mathrm{ml}$ of water was given a test sample.

\subsection{Study design}

Firstly, scanning was performed for the young age group followed by middle age group in the early hours, 7.30 am to 10.00 am at MGMGH, Tiruchirapalli, Tamil Nadu. Subjects were asked to consume the given amount of test sample at a normal pace within 15 minutes. After ingestion of the test sample and the prescribed amount of water, subjects were made to lie in the right decubitus position for a total time of two hours of digestion. Scheme 1 represents the whole scanning procedure followed during the present study.

\subsection{MRI scanning of human volunteers}

MRI of all subjects was performed using a Siemens $1.5 \mathrm{~T}$ magnetron scanner. Whole scanning procedure was followed according to the procedure mentioned by Gopirajah and team (Gopirajah, Raichurkar, Wadhwa, \& Anandharamakrishnan, 2016). Cine dynamic scan was performed to assess the antral wave characteristics of the stomach in response to apple ingestion. Gastric motility scan was performed in axial plane using dynamic motility cine scan with free-breathing, to determine the ACW characteristics of the stomach after ingestion of test meal. A total of 120 measurements were taken for every 1 minute scan period for every 5 minutes for the first $30 \mathrm{~min}$ and for every 15 minutes to the rest of the 1.5 hours of study time. Table 1 lists different scanning parameters used during gastric motility scan in MRI.

Table 1: List of parameters used for gastric motility scan in MRI machine

\begin{tabular}{|c|c|}
\hline Parameters & Gastric motility scan \\
\hline Echo time (ms) & 1.44 \\
\hline Repetition time (ms) & 50.1 \\
\hline Slice thickness (mm) & 6 \\
\hline No. of slices & 1 \\
\hline Distance factor $(\%)$ & 20 \\
\hline Flip angle $\left({ }^{\circ}\right)$ & 80 \\
\hline Scan time (s) & 60 \\
\hline Field of view (mm) & 340 \\
\hline
\end{tabular}

\subsection{Assessment of gastric motility}

ACW characteristics like width, amplitude, frequency, occlusion percentage and gastric motility index (GMI) were determined using in-house analysis software associated with the Siemens MRI machine. calculations were performed based on the method explained Kwiatek and co-workers (Kwiatek et al., 2006). A central line called antropyrloral axis was drawn from the upper part of the stomach to pylorus, i.e 8 $\mathrm{cm}$ distant from pylorus which serves as a base for determining the contraction frequency and speed. Tips and bases of ACW waves along the antral wall were identified to calculate occlusion percentage $(\%)$, width and amplitude $(\mathrm{cm})$ of the propagating waves, thus determining the gastric motility parameters. For assessing the speed and frequency of the wave, successive dynamic sequence images for about $20 \mathrm{~s}$ were taken in which antropyloral axis can be drawn so that propagation of the antral wave is traced clearly (Baba et al., 
2009) ${ }^{[2]}$. Below are the formulas used in determining the meal volume and gastric motility parameters.

Meal volume $=($ Area of the meal in each slice $) *$ slice thickness

Occlusion percentage $=([1-$ occlusion diameter $/$ antral diameter] * 100)

Width of $\mathrm{ACW}=(\mathrm{W} 1+\mathrm{W} 2) / 2$

Amplitude of ACW $=(\mathrm{A} 1+\mathrm{A} 2) / 2$

Gastric motility index $=(($ Distance of propagation of $\mathrm{ACW}$ wave) $)^{2}$ ) / time

Contraction speed $=$ No. of. Contractions $/$ minute

\subsection{Statistical analysis}

All the statistical analyses required for the study were performed in Graphpad Prism 8 software. Unpaired t-test was performed to assess the ACW characteristics in two age groups. All the in vivo experiments were done in triplicates and results are expressed in the form of mean \pm standard deviation.

\section{Results}

All the participants, three from young and three from middle age group underwent MRI scanning successfully. Despite the small sample size, the present study exhibited excellent feasibility in assessing the gastric motility. Good contrast images were obtained at high speed. A clear demarcation between axial plane images of the stomach contents and wall movements were obtained. All the calculations were carried out taking pylorus as an anchoring point and drawing an axis called antropyloral axis away from pylorus till a distance of 8 cm (Gopirajah et al., 2016) ${ }^{[10]}$. It was used as a reference line to determine the stomach wall movement during digestion of apple. Figure 1 shows the propagation of ACWs and their parameters that are to be determined.

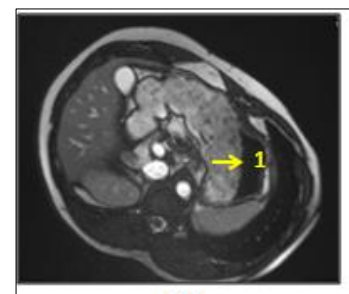

(a)

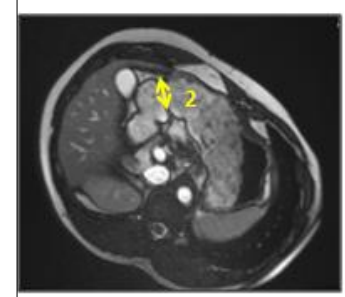

(b)

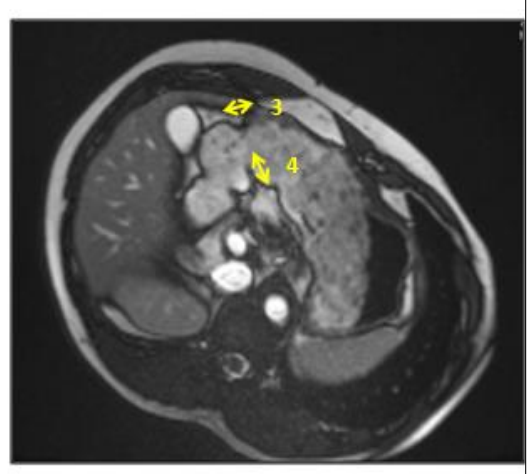

(c)
Fig 1: Axial plane images of dynamic motility scan depicting the position of ACWs and other related parameters,

(a) 1. Propagating ACWs, (b) 2. Occlusion diameter (c) 3. Width of ACW, 4. The amplitude of the wave.

The propagation speed of the ACW wave in 20-30 years age group was $3.5 \pm 0.01 \mathrm{~mm} / \mathrm{s}$ while it was $3.3 \pm 0.03 \mathrm{~mm} / \mathrm{s}$ for middle age grouped volunteers. No significant difference was found between the propagation speed of two different age groups $(\mathrm{P}=0.51)$. The average frequency of the ACW was found to be $22.5 \pm 0.5$ and $24.77 \pm 2.17$ seconds in young and middle age group respectively $(\mathrm{P}=0.423)$. Figure 2 shows the plots obtained for frequency and propagation speed in two different age groups.

Occlusion percentage in the antrum region of both the age groups are found to be similar without any significant difference $(\mathrm{P}=0.99)$. Similar results were also found with average contractions per minute, i.e., 2.67 \pm 0.06 and $2.43 \pm 0.22$ in young and middle age groups respectively $(\mathrm{P}=0.33)$. Width and amplitude of the ACW's were also determined, in which no notable difference was observed between two age groups $(\mathrm{P}=0.72)$. Gastric motility index of 20 -30 years age group was $28.3 \pm 0.06$ and it was $2.61 \pm 0.23$ $\mathrm{mm}^{2} / \mathrm{s}$ for middle age group, with no marked difference $(\mathrm{P}=$ 0.61). Table 2 lists some of the ACW values obtained in two different age groups.

Table 2: ACWs in young and middle-aged volunteers

\begin{tabular}{|c|c|c|}
\hline ACW Parameters & $\begin{array}{c}\text { Obtained averages } \\
(\mathbf{2 0 - 3 0} \text { Years })\end{array}$ & $\begin{array}{c}\text { Obtained averages } \\
(\mathbf{4 0 - 5 0} \text { Years })\end{array}$ \\
\hline ACW speed $(\mathrm{mm} / \mathrm{s})$ & $3.5 \pm 0.01^{\mathrm{a}}$ & $3.3 \pm 0.03^{\mathrm{a}}$ \\
\hline Frequency $(\mathrm{s})$ & $22.5 \pm 0.5^{\mathrm{a}}$ & $24.77 \pm 2.17^{\mathrm{a}}$ \\
\hline Contractions per min & $2.67 \pm 0.06^{\mathrm{a}}$ & $2.43 \pm 0.22^{\mathrm{a}}$ \\
\hline Percentage occlusion $(\%)$ & $37.99 \pm 9.56^{\mathrm{a}}$ & $37.9 \pm 5.87^{\mathrm{a}}$ \\
\hline GMI $\left(\mathrm{Cm}^{2} / \mathrm{s}\right)$ & $2.83 \pm 0.06^{\mathrm{a}}$ & $2.61 \pm 0.23^{\mathrm{a}}$ \\
\hline Width $(\mathrm{Cm})$ & $1.14 \pm 0.13^{\mathrm{a}}$ & $0.97 \pm 0.42^{\mathrm{a}}$ \\
\hline Amplitude $(\mathrm{Cm})$ & $0.95 \pm 0.19^{\mathrm{a}}$ & $1.11 \pm 0.34^{\mathrm{a}}$ \\
\hline
\end{tabular}

Data are expressed as average \pm SD of the variables per group, $\mathrm{n}=3$. Means with a different superscript in the same row indicate the significant difference $(p<0.05)$.

\section{Discussions}

Very few studies reported the effect of ageing on gastric motility while most of the studies are focussed on gastric motor function as a whole. In a study on determination of postprandial antral wave frequency, no significant difference was reported among the two different age groups, young and old age (Madsen \& Graff, 2004) ${ }^{[20]}$. Bonner and co-workers in their study on varying the type of meal among four different age groups reported that no significant differences were found between the age groups which consumed the same type of meal, while significant differences were observed in case of the varying meal (Bonner et al., 2015) ${ }^{[3]}$. The present study also reported similar results following the above literature reports. There was no significant difference found among the assessed ACW characteristics between the two different age groups. Above findings can be attributed to considering the same type of test meal and selection of subjects with healthy ageing without any disorders. ACW characteristic parameters reported in this study were in range with the values reported by Gopirajah and co-workers in a study made on comparison of two fibre loaded solid meals of different viscosity and various other literature reported values

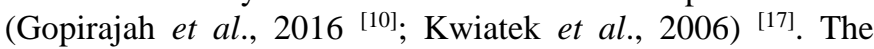
altered gastric motor function can be associated with various intrinsic or extrinsic factors, which in turn also affect the glycemic response.

Extrinsic factors like food-its physical state, physical and chemical properties and intrinsic factors like pyloric contractile activity, tonic pressures, vagal activity and some digestive disorders play a key role while age and sex only have a minor effect (Graff et al., 2001; Horowitz et al., 1984) [14]. Many studies also confirmed a positive relationship between the ACW propagation speed and half emptying times, i.e., more rapid the waves propagate, faster the emptying of food. Gastric waves are observed to be slow in 
case of hyperglycaemic patients (Marathe et al., 2015) [22]. Average contractions per minute of the human stomach are 3, while it varies based on various external and internal influencing conditions. ACW characteristics also depend on various food properties like caloric density, viscosity and physical state of meal and health status of individuals (Alyami et al., 2019; Calbet \& MacLean, 1997; Sachdeva et al., 2013) [27]. Baba and team determined the motility of two populations; healthy and gastroparesis patients, in which they found that motility parameters assess were significantly lower in gastroparesis patients compared to healthy individuals (Baba et al., 2009) ${ }^{[2]}$. These changes in gastric motor function can be attributed to pyloric contractibility, particularly sustained tonic pressure, terminating the transpyloric flow (Moore, Tweedy, Christian, \& Datz, 1983; Salles, 2007). These differences are more commonly observed upon ingestion of liquid foods while solid foods preserve the peristaltic movements. Due to the consideration of apple, a solid meal as a test sample, no differences in motility parameters were observed between the two different age groups.

\section{Conclusion}

Studies on gastric motility in response to ingestion of particular foods provide deep insight into the fate of food and its interaction with the gastric system. Also, understanding the various factors that affect gastric motility is of great significance. In addition to recent studies on engineering the foods to increase their residence times in the gastric region, research on altering the gastric motility has taken up the era. Hence studies on gastric motility and their characteristics have drawn attention in both food and medical fields. The present study focused on determining the variation of gastric motility in two different age groups, in response to ingestion of apple. There was no significant difference observed between the two age groups, i.e., young and middle in terms of all the antral contraction wave parameters calculated. This result confirms the insignificant effect of age on gastric motor function upon solid ingestion, while further variation in age, i.e., elderly group and varying meal type on motility can be an interesting area of future research.

\section{References}

1. Alyami J, Ladd N, Pritchard SE, Hoad CL, Sultan AA, Spiller RC et al. Glycaemic, gastrointestinal and appetite responses to breakfast porridges from ancient cereal grains: A MRI pilot study in healthy humans. Food Research International, 118(November) 2019, 49-57. https://doi.org/10.1016/j.foodres.2017.11.071

2. Baba S, Sasaki A, Nakajima J, Obuchi T, Koeda K, Wakabayashi G et al. Assessment of gastric motor function by cine magnetic resonance imaging. Journal of Gastroenterology and Hepatology (Australia) 2009;24(8):1401-1406. https://doi.org/10.1111/j.14401746.2009.05891.x

3. Bonner JJ, Vajjah P, Abduljalil K, Jamei M, RostamiHodjegan A, Tucker GT et al. Does age affect gastric emptying time? A model-based meta-analysis of data from premature neonates through to adults. Biopharmaceutics and Drug Disposition 2015;36(4):245257. https://doi.org/10.1002/bdd.1937

4. Bornhorst GM, Paul Singh R. Gastric Digestion In Vivo and In Vitro: How the Structural Aspects of Food Influence the Digestion Process. Annual Review of Food
Science and Technology 2014;5(1):111-132. https://doi.org/10.1146/annurev-food-030713-092346

5. Brogna A, Ferrara R, Bucceri AM, Catalano F, Natoli G, Leocata V. Gastric emptying rates of solid food in relation to body mass index: An ultrasonographic and scintigraphic study. European Journal of Radiology 1998;27(3):258-263. https://doi.org/10.1016/S0720048X(97)00081-8

6. Calbet JAL, MacLean DA. Role of caloric content on gastric emptying in humans. Journal of Physiology 1997;498(2):553-559. https://doi.org/10.1113/jphysiol.1997.sp021881

7. Camps G, De Graaf K, Smeets PAM. Men and women differ in gastric fluid retention and neural activation after consumption of carbonated beverages. Journal of Nutrition 2018;148(12):1976-1983. https://doi.org/10.1093/jn/nxy230

8. Du T, Hill L, Ding L, Towbin AJ, Dejonckheere M, Bennett $\mathrm{P}$ et al. Gastric emptying for liquids of different compositions in children. British Journal of Anaesthesia 2017;119(5):948-955.

https://doi.org/10.1093/bja/aex340

9. Gopirajah R, Anandharamakrishnan C. Methods integrating physical mechanisms underlying the food digestion and release of nutrients in human stomach. J Nutr Nutr Epidemiol 2014, 1-13.

10. Gopirajah R, Raichurkar KP, Wadhwa R, Anandharamakrishnan $\mathrm{C}$. The glycemic response to fibre rich foods and their relationship with gastric emptying and motor functions: An MRI study. Food and Function 2016;7(9):3964-3972. https://doi.org/10.1039/c6fo00659k

11. Graff J, Brinch K, Madsen JL. Gastrointestinal mean transit times in young and middle-aged healthy subjects. Clinical Physiology 2001;21(2):253-259. https://doi.org/10.1046/j.1365-2281.2001.00308.x

12. Hausken T, Mundt M, Samsom M. Low antroduodenal pressure gradients are responsible for gastric emptying of a low-caloric liquid meal in humans. Neurogastroenterology and Motility 2002;14(1):97-105. https://doi.org/10.1046/j.1365-2982.2002.00307.x

13. Hellström PM, Samuelsson B, Al-Ani AN, Hedström M. Normal gastric emptying time of a carbohydrate-rich drink in elderly patients with acute hip fracture: A pilot study. BMC Anesthesiology 2017;17(1):1-5. https://doi.org/10.1186/s12871-016-0299-6

14. Horowitz M, Maddern GJ, Chatterton BE, Collins PJ, Harding PE, Shearman DJ. Changes in gastric emptying rates with age. Clinical Science 1984;67(2):213-218. https://doi.org/10.1042/cs0670213

15. Kong F, Singh RP. A model stomach system to investigate disintegration kinetics of solid foods during gastric digestion. Journal of Food Science 2008;73(5), 202-210. https://doi.org/10.1111/j.1750-3841.2008.00745.x

16. Kong Fanbin, Singh RP. Digestion of raw and roasted almonds in simulated gastric environment. Food Biophysics 2009;4(4):365-377. https://doi.org/10.1007/s11483-009-9135-6

17. Kwiatek MA, Steingoetter A, Pal A, Menne D, Brasseur JG, Hebbard GS et al. Quantification of distal antral contractile motility in healthy human stomach with magnetic resonance imaging. Journal of Magnetic Resonance Imaging 2006;24(5):1101-1109. 
https://doi.org/10.1002/jmri.20738

18. Lamond AR, Janssen AEM, Mackie A, Bornhorst GM, Bakalis S, Gouseti O. An engineering perspective on human digestion. Interdisciplinary Approaches to Food Digestion 2019, 255-273. https://doi.org/10.1007/978-3030-03901-1_12

19. Liu W, Jin Y, Wilde PJ, Hou Y, Wang Y, Han J. Mechanisms, physiology, and recent research progress of gastric emptying. Critical Reviews in Food Science and Nutrition 2020;0(0):1-14. https://doi.org/10.1080/10408398.2020.1784841

20. Madsen JL, Graff J. Effects of ageing on gastrointestinal motor function. Age and Ageing 2004;33(2):154-159. https://doi.org/10.1093/ageing/afh040

21. Maes BD, Ghoos YF, Geypens BJ, Hiele MI, Rutgeerts PJ. Relation between gastric emptying rate and energy intake in children compared with adults. Gut 1995;36(2):183-188. https://doi.org/10.1136/gut.36.2.183

22. Marathe CS, Horowitz M, Trahair LG, Wishart JM, Bound M, Lange $\mathrm{K}$ et al. Relationships of early and late glycemic responses with gastric emptying during an oral glucose tolerance test. Journal of Clinical Endocrinology and Metabolism 2015;100(9):3565-3571. https://doi.org/10.1210/JC.2015-2482

23. Marciani L, Young P, Wright J, Moore R, Coleman N, Gowland PA et al. Antral motility measurements by magnetic resonance imaging. Neurogastroenterology and Motility 2001;13(5):511-518. https://doi.org/10.1046/j.1365-2982.2001.00285.X

24. Moore JG, Tweedy C, Christian PE, Datz FL. Effect of age on gastric emptying of liquid-solid meals in man. Digestive Diseases and Sciences 1983;28(4):340-344. https://doi.org/10.1007/BF01324951

25. Pal A, Brasseur JG, Abrahamsson B. A stomach road or "Magenstrasse" for gastric emptying. Journal of Biomechanics 2007;40(6):1202-1210. https://doi.org/10.1016/j.jbiomech.2006.06.006

26. Parkman HP. Gastric Emptying Studies. Gastrointestinal Motility Disorders 2018, 309-315.

27. Sachdeva P, Kantor S, Knight LC, Maurer AH, Fisher RS, Parkman HP. Use of a high caloric liquid meal as an alternative to a solid meal for gastric emptying scintigraphy. Digestive Diseases and Sciences 2013;58(7):2001-2006. https://doi.org/10.1007/s10620013-2665-2

28. Salles N. Basic mechanisms of the aging gastrointestinal tract. Digestive Diseases 2007;25(2):112-117. https://doi.org/10.1159/000099474

29. Sandhu KS, El Samahi MM, Mena I, Dooley CP, Valenzuela JE. Effect of pectin on gastric emptying and gastroduodenal motility in normal subjects. Gastroenterology 1987;92(2):486-492. https://doi.org/10.1016/0016-5085(87)90146-6

30. Schulze K. Imaging and modelling of digestion in the stomach and the duodenum. Neurogastroenterology and Motility 2006;18(3):172-183. https://doi.org/10.1111/j.1365-2982.2006.00759.x 